\title{
The effect of brown algae Nizimuddinia zanardinii on biochemical parameters and histopathological changes induced by cholestatic liver fibrosis in male rats
}

\author{
Modara Nasiri \\ Islamic Azad University \\ Ramin Hajikhani \\ Islamic Azad University \\ Pejman Mortazavi ( $\sim$ sp.mortazavi@gmail.com ) \\ Islamic Azad university \\ Mahsa Ale Ebrahim \\ Tehran University of Medical Sciences \\ Maryam Bananaj \\ Islamic Azad University
}

\section{Research Article}

Keywords: antifibrotic, BDL, Cholestasis, hepatoprotective, Nizimuddinia zanardinii

Posted Date: February 14th, 2022

DOI: https://doi.org/10.21203/rs.3.rs-1305614/v1

License: (a) (i) This work is licensed under a Creative Commons Attribution 4.0 International License.

Read Full License 


\section{Abstract}

Background: Liver fibrosis is an important health problem in the world; the excessive deposition of type 1 collagen is the most characteristic feature of liver fibrosis. Algae is one of the natural resources that contains biologically active compounds that have anti-inflammatory, antioxidant and immunestimulating properties. In this study, the effect of brown algae Nizimuddinia zanardinii on liver damage caused by cholestatic liver fibrosis in rats was evaluated.

Material and Methods: 54 male rats were randomly classified in nine groups: control, sham, BDL, treatment and Nizimuddinia control. In the treatment group, after BDL, rats were given Nizimuddinia zanradinii extract via intragastric gavage for 45 days (once per day). parameters contains ALT, AST, ALP, cholesterol, triglyceride, albumin, total protein, SOD and CAT and histopathological assessments evaluated.

Results: Treatment with Nizimuddinia zanardinii significantly weakened these alterations. In order to, in the treatment groups, TGF- $\beta 1$ expression was severe, noticeable and low, respectively. In treatment groups, a-SMA expression was remarkable and mildly observed in hepatocytes and hyperplastic bile ducts, respectively.

Conclusions: Based on this study, the $N$. zanardinii extract may protect the liver and have anti-fibrotic effects through its antioxidant and reducing the expression of TGF- $\beta 1$ and a-SMA.

\section{Introduction}

The use of current concepts in chronic cholestatic diseases highlights the pro-fibrotic properties of the accumulation of hydrophobic bile salts in cholestasis. This well-accepted hypothesis was proposed in the 1970s [1,2] and to this day, the bile salts accumulation of hydrophobic is seen as a stimulus force for fibrosis in cholestatic liver disease [3]. However, the mechanisms of fibrosis in the cholestatic liver are complex, it has been well established that the accumulation of toxic and hydrophobic bile salts in the liver balances the oxidant/peroxidant in favor of increasing the activity of reactive oxygen species (ROS) and these free radicals [4-6]. Then, it boosts the inflammatory response that triggers collagen production in the liver [7]. Fibrosis is the creation of a framework of granulation tissue consisting of new vessels and an extracellular matrix that replaces the original lost tissue [8]. Some effects of cholestasis include the accumulation of bilirubin, bile acids, and cholesterol, which are normally secreted into the bile [2]. Whatever the cause of cholestasis, it eventually leads to damage to the hepatocytes and leads to liver dysfunction. The accumulation of bile salts is responsible for part of the damage to hepatocytes $[9,10]$. During liver injury, hepatic stellate cells (HSCs) are converted to myofibroblasts, which increase fibrillar collagen levels, and the intracellular microfilament protein expresses a smooth muscle actin (a-SMA), which in turn traditionally used as an activated marker protein of the HSC phenotype [11-13]. Also, transforming growth factor-beta1 (TGF- $\beta 1$ ) is a major mediator in the pathogenesis of hepatic fibrosis 
that activates SMAD-dependent and independent pathways to display its biological activity. TGF- $\beta$ is known to exert its biological effects by activating downstream mediators [14].

There are various plants that due to their reported effects such as antioxidative, liver protective, antiapoptotic and anti-inflammatory effects are potential candidates for use in relieving symptoms or improving cholestatic liver damage [15]. Recent findings show that algae have antiviral, antibacterial, antifungal and antitumor properties among many other marine plants $[16,17]$. One of the important nutritional benefits of brown algae, is the high presence of unsaturated fatty acids, especially $n-3$ and $n-6$ unsaturated fatty acids $[18,19]$. Nizamuddinia zanardinii is a tropical brown macro-algae which is an excellent source of protein, vitamins, essential fatty acids and minerals. So far, numerous biological compounds with diverse applications such as antibiotic, antiviral, antifungal and anti-cancer effects have been identified and derived from multicellular algae $[20,21]$. In addition, brown algae are a rich source of omega-3 [22]. According to various reports, unsaturated fatty acids with several double bonds account for more than $30 \%$ of the total fatty acids in diatoms and brown algae. Unsaturated fatty acids with several double bonds, including omega-3 and omega- 6 , are known to be healthy compounds useful for human health [23]. Recent experiments with omega-3 enriched fatty acids, or as the predominant source of lipids, have shown encouraging results in the treatment of cholestatic patients [24-26]. Since no studies have been performed on the effect of Nizimuddinia zanardinii on the liver and hepatic diseases, this study was performed to investigate the effect of Nizimuddinia zanardinii on hepatic cholestasis induced BDL.

\section{Material And Methods}

\section{Ethics statement}

During the research period, all Ethical Considerations and Work Protocols on Laboratory Animals were in accordance with the recommendations established by the Laboratory Animal Ethics Committee and Supervision of Islamic Azad University, Tehran-North Branch, Tehran, Iran, as well as US NIH Guidelines (National Research Council of USA, 1996). The protocols were approved by the Ethics Committee of Islamic Azad University, Tehran-North Branch, Tehran, Iran. As well as, many efforts were made to minimize suffering, and all surgeries were performed under deep anesthesia. The study is reported in accordance with ARRIVE guidelines (https://arriveguidelines.org).

\section{Animals}

Fifty-four adult male Wistar rats weighing approximately 230-250 g were purchased from the Pasteur Institute of Iran and transferred to the animal room of the Faculty of Basic Science, Islamic Azad University, Tehran-North Branch, Tehran, Iran with Ethics committee number IR.IAU.TNB.REC.1400.052.

The animals were kept in a laboratory animal breeding center with fiberglass cages and under standard conditions with a temperature of $22 \pm 2{ }^{\circ} \mathrm{C}$ and a light cycle of 12 hours of light and 12 hours of darkness and relative humidity of $40-60 \%$. For feeding the animals, special food for rats (plates) was 
prepared from Pars Animal Feed Company of Tehran and clean piped water was provided to the animals through drinking glasses without any restrictions.

\section{Experimental design and BDL operation}

After accommodation for one week, the rats were randomly classified into 9 groups of six animals each as follows: Group 1 (control): healthy intact animals that received daily distilled water as a drug solvent. Group 2 (Sham): the operated animals without BDL surgery which received distilled water daily as a drug solvent. Group 3 (BDL): Animals have undergone BDL surgery which received distilled water daily. Groups 4-6 (Experimental treatment): BDL-operated animals received daily treatment of brown algae extract at doses of 50,100 or $200 \mathrm{mg} / \mathrm{kg}$ bw. Group 7-9 (Nizimuddinia control): intact animals that received daily treatment of brown algae extract at doses of 50,100 or $200 \mathrm{mg} / \mathrm{kg} \mathrm{bw}$. The animals received brown algae extract dissolved in distilled water once a day by intragastric gavage. The volume of treatment was $0.5 \mathrm{ml}$ and the duration of treatment was 45 consecutive days $[27,28]$. Bile duct ligation (BDL) surgery was performed according to the standard method of Uchinami et al [29]. Briefly, each animal was completely anesthetized by intraperitoneal (ip) injection of a mixture of ketamine ( $90 \mathrm{mg} / \mathrm{kg} \mathrm{bw}$ ) and xylazine (10 mg/kg bw). An abdominal incision was made from the midline. The common bile duct was identified and doubled ligated with a 4-0 nylon suture (AILEECo. Ltd., Busan, Korea) at two points (just below the junction of the hepatic duct and before the entrance to the pancreatic duct). The bile duct was then cut between these two points. At the end of the operation, $2 \mathrm{ml}$ of sterile saline was injected into the peritoneum, followed by precise sutures of the peritoneum and muscles, as well as skin wounds. The animals were then allowed to recover on a heat pad [29]. In sham rats, an abdominal incision was made without ligation of the common bile duct.

\section{Preparation of Nizimuddinia zanardinii extract}

The algae was prepared from Chabahar Port, Sistan and Baluchestan, Iran. The collected algae were stored in an ionolytic box containing ice and then transferred to the laboratory. The algae were thoroughly washed and immersed in distilled water (to remove solutes), and their water were changed for several hours. This was repeated up to three times, after which the algae were dried and completely pulverized by an electric mill. To prepare the ethanolic extract of the studied algae, $200 \mathrm{~g}$ of each algae powder sample was soaked in $80 \%$ ethanol solvent. Then, they were incubated for 24 hours at $100 \mathrm{rpm}$ and room temperature. The extract extraction process was repeated two more times and then the extracts were filtered using Whatman No. 1 filter paper; Solubilization was performed under the hood and the extract was concentrated and kept at $4^{\circ} \mathrm{C}$ for later use [30, 31].

\section{Sampling and biochemical evaluation}


After the experimental period, the animals were fasted for 12 hours. Under anesthesia with i.p. injection of ketamine $(90 \mathrm{mg} / \mathrm{kg} \mathrm{bw})$ and xylazine $(10 \mathrm{mg} / \mathrm{kg} \mathrm{bw})$ the blood and livers were collected. After a $30-$ minute pause for blood clotting, the samples were centrifuged at $2500 \mathrm{rpm}$ for 5 minutes to separate the serum from the blood and the serum levels of ALT, AST, ALP, cholesterol, triglyceride, total bilirubin, albumin and total protein were determined based on IFCC method (International Federation of Clinical Chemistry and Laboratory Medicine) and the utilized kits for evaluating the biochemical parameters by autoanalyzer device (BT1500, Italy) [32].

\section{Measurement of hepatic superoxide dismutase (SOD) and catalase activities (CAT)}

A part of the liver tissue of animals in all groups as fixed in 10\% formalin buffer solution to prepare paraffin blocks from them after performing conventional tissue processing methods. Another part of the liver was used to prepare liver homogenate. The prepared homogeneous solutions were then poured into several follicles (equal volumes) and centrifuged by refrigerated centrifuge at $4{ }^{\circ} \mathrm{C}$ and $9000 \mathrm{rpm}$ for 20 minutes. The milky supernatant was then collected to assay the activities of CAT and SOD activity was determined using the CAT and SOD assay kit (Pars Azmoon, Tehran, Iran) according to the manufacturers' protocol that was assayed as described previously [33]. Briefly, $0.2 \mathrm{ml}$ of homogeneity was added to $1.2 \mathrm{ml}$ of $50 \mathrm{mM}$ phosphate buffer $(\mathrm{pH}=7.5)$, the reaction starting with the addition of 1.0 $\mathrm{ml}$ of $30 \mathrm{mM} \mathrm{H}_{2} \mathrm{O}_{2}$ solution. Absorption reduction was measured at $240 \mathrm{~nm}$ at 30 -second intervals for 30 minutes. A unit $(U)$ of the activity of this enzyme is defined as the amount of enzyme that obtains the value $K=1$, where $K$ is the rate constant of the enzyme. Activity is expressed as a unit per $\mathrm{mg}$ of protein (U/mg protein) [33].

\section{Histopathological examination}

Trichrome staining is used to detect increased collagen deposition and to determine the severity of fibrosis in the liver tissues. 4-6 $\mu \mathrm{m}$-thick sections cut from the liver of all groups were placed in xylene (2.5 minutes) and descending alcohol series $(100,90,80,80,70$, and $50 \%)$ for deparaffinization. Then, the Sigma-Aldrich Masson's Trichrome Stain Kit (HT15) was applied to the sections. They were washed with alcohol and xylene and covered with Entellan and light microscopic examinations were performed in a blinded fashion [34, 35]. The pathological findings were qualitative, and the liver damage in different groups was scored based on a modified method by Sant'Anna et al [36] using trichrome staining. In this method, 10 areas were randomly examined in each sample and the average injury was considered as a single score. The damage rating is as follows: necrosis: $0=$ no necrosis, $1=$ local damage less than $25 \%$, 2 = local damage between 25-50\%, 3 = extensive but local necrosis, 4 = extensive necrosis; infiltration of inflammatory cells: 0 = no inflammation, 1 = focal inflammation less than $25 \%, 2$ = focal inflammation between $25-50 \%, 3$ = extensive but localized inflammation, 4 = extensive inflammation; connective tissue: $0=$ no connective tissue, 1 = collagen deposition without a wall mattress, $2=$ incomplete wall mattress, 3 
$=$ full and thin wall, 4 = full and thick wall; bile duct hyperplasia: $0=$ no hyperplasia, $1=$ less than $25 \%$ per lobule, 2 = 25-50\% per lobule, 3 = extensive but localized, 4 = extensive [36].

\section{Immunohistochemistry staining}

Immunohistochemistry staining was performed on liver tissue sections to determine alpha smooth muscle actin (a-SMA), the most commonly used protein that is increased in liver fibrosis, and transforming growth factor- $\beta 1$ (TGF $\beta 1$ ), which is increased in liver injury are considered liver injuries. Liver sections were used and dehydrated before epitope recovery in novocaster solution in toluene (Leica Biosystems, Germany). After neutralizing the endogenous peroxidase with $3 \% \mathrm{H}_{2} \mathrm{O}_{2}$ for 10 minutes, the sections were incubated with blocking solution at $4{ }^{\circ} \mathrm{C}$ with anti-TGF- $\beta 1$, $a-S M A$ antibodies (1: 100, dilution). The detection was performed using a polymer detection system (Novolink max polymer detection system, Novocastra Leica Biosystems) and DAB (3,30-Diaminobenzidine, Novocastra Leica Biosystems) as the chromogenic substrate. Hematoxylin staining was used before dehydration and installation. Images were assessed by light microscopy (Olympus BX43, Hamburg, Germany) [37].

\section{Statistical analysis}

All data were statistically analyzed by SPSS ver20 using one-way analysis of variance (One-way-ANOVA) and Tukey post hoc test. The results are presented as Mean \pm S.E.M. $P<0.05$ was considered statistically significant.

\section{Results}

\section{Effects of Nizimuddinia zanardinii hydroalcoholic extract on liver biochemical parameters in the studied groups}

As shown in Fig. A, BDL increased significantly the serum levels of ALT, AST, ALP and triglyceride as the key biomarkers of liver injury compared with the sham group $(\mathrm{P}<0.001)$. Nizimuddinia extracts in all doses of 50,100 and $200 \mathrm{mg} / \mathrm{kg}$ decreased significantly the ALT level in all treatment groups compared to the BDL group ( $\mathrm{P}<0.001$ ), in addition, Nizimuddinia just in Nizi200 group (normal+Nizi200 mg/kg) decreased significantly the level of ALT compared with the control group. Also, ALP in treatment groups with 100 and 200 doses of Nizimuddinia reduced significantly contrast to BDL group $(P<0.001)$. On the other hand, Nizimuddinia attenuated ALP significantly in all treatment groups $(P<0.001)$. Moreover, triglyceride in treatment groups with 100 and 200 doses of Nizimuddinia decreased significantly compared to the BDL group ( $\mathrm{P}<0.001)$. Except for the mentioned case, no significant change in ALT, AST, ALP and triglyceride parameters was observed in the Nizimuddinia groups (normal+Nizi50, 100 and 200 $\mathrm{mg} / \mathrm{kg}$ ). 
As indicated in Fig. B, the BDL group demonstrated significantly increase in the serum levels of cholesterol and total bilirubin compared with the sham group $(P \leq 0.001)$. No significant change in the cholesterol, total bilirubin, albumin and total protein biochemical factors was observed in the Nizimuddinia groups. Whereas, treatment of BDL rats with Nizimuddinia reduced significantly cholesterol and total bilirubin levels in all treatment groups in a dose-dependent pattern $(P \leq 0.001)$. On the other hand, the total protein showed a reduction in the BDL rats that were treated with

Nizimuddinia significantly increased the total protein compared with the BDL rats $(P \leq 0.001)$. Also, BDL diminished significantly the serum albumin compared to the control group ( $P \leq 0.001)$. Treatment of BDL rats with Nizimuddinia extract increased the serum albumin level in all treatment groups in a dosedependent pattern $(P \leq 0.001)$.

Moreover, No significant change was observed in the activities of SOD and CAT compared to the control group $(P \geq 0.001)$. In addition, $B D L$ decreased significantly the antioxidant enzyme activities of SOD and CAT $(P \leq 0.001)$. Treatment of BDL rats with Nizimuddinia extract enhanced significantly the level of SOD enzyme in treatment groups with 100 and 200 doses compared to the BDL group ( $P \leq 0.001)$. While, CAT activity increased significantly in all treatment groups contrast to the BDL group $(P \leq 0.001)$. Therefore, treatment with Nizimuddinia zanardinii showed positive effects on SOD in 100 and 200 doses and CAT in all doses (Fig. C).

\section{Histopathological evaluation}

The results of histopathological evaluations of trichrome-Mason staining in the BDL group, lesions include extensive but localized necrosis of hepatocytes and infiltration of focal inflammatory cells between $25-50 \%$, extensive bile duct hyperplasia, infiltration of connective tissue with complete and thin wall between necrotic and regenerated hepatocytes and incomplete hepatic lobules. In the studied groups, the degrees and severity of lesions were different, which according to the table 1, the experimental healthy groups were completely healthy and similar to the control group. While in the treatment group 50, extensive but local necrosis and inflammation was observed, in addition, it had complete and thin connective tissue and extensive hyperplasia was seen. Whereas, in the treatment group of 100 was observed local necrosis between 25 to $50 \%$, connective tissue with incomplete wall and extensive but local hyperplasia. Recovery in the tissue of the 200 treatment group was characterized by local necrosis less than $25 \%$, focal inflammation less than $25 \%$, increased collagen without wall, and hyperplasia less than $25 \%$ (Fig. D).

As shown in Fig. E, no significant tissue changes were observed in control group experimental healthy groups which were healthy and received Nizimuddinia zanardinir, whereas the BDL group showed severe histological changes compared with the sham group and in control group. Major lesions include placental fibrosis, which can be detected by the deposition of collagen (connective tissue) as thin and complete walls. Also, extensive but local necrosis, extensive bile duct hyperplasia and infiltration of focal mononuclear inflammatory cells (lymphocytes) were observed between $25-50 \%$. These changes were 
seen in almost all lobules, although they were more widespread in the central lobular region (Fig E3). In the treatment groups with Nizimuddinia zanardinii the rate of necrosis, bile duct hyperplasia, infiltration of inflammatory cells and collagen deposition was reduced in a dose-dependent manner (Fig E 4-6).

\section{Immunohistochemical staining}

Immunohistochemistry $(\mathrm{IHC})$ is a method used to determine the expression of biomarkers in tissue. Although quantitatively less sensitive than immunological methods such as Western blotting and ELISA, it makes it possible to observe processes in the context of intact tissue. This method is especially useful for assessing the progression and treatment of diseases such as cancer. Immunohistochemical staining is performed in the presence of antibodies, which identify the target proteins. Because antibodies are highly specific, they bind only to their respective proteins in tissue sections. Therefore, the interaction between antibody-antigen is determined by tissue staining. In this method, the enzyme binds to the fission of the antibody and a color deposit is created at the site of the protein, which can be examined with a light microscope [38].

The results of TGF- $\beta 1$ expression in Nizimuddinia zanardinii hydroalchoholic extract treatment, sham and control groups are shown in Fig. F.

Based on Fig. $\mathrm{H}$, the histopathological evaluation with immunohistochemical staining based TGF- $\beta 1$, the positive criterion for TGF- $\beta 1$ expression is a browning of the cytoplasm in $50 \%$ of hepatocytes and cell nuclei [39], lack of TGF- $\beta$ expression of hepatocytes around the central vein (CV) and other hepatocytes observed in liver tissues with control (Fig. H1). While in the BDL group (Fig. H3), severe expression of TGF- $\beta 1$ in hyperplastic bile duct cells and hepatocytes are shown; in other words, TGF- $\beta 1$ expression was highly positive around the central vein and hyperplasia bile duct cells (Fig. H3). The treatment 50 group (Fig. H4) showed severe expression of TGF- $\beta$ in hepatocytes and hyperplastic bile duct cells; as well as, in the treatment 100 group (Fig. H5) was observed significant expression of TGF- $\beta$ in hepatocytes and hyperplastic bile duct cells. Also, in the treatment 200 group (Fig. H6) showed low TGF- $\beta$ expression in hepatocytes and hyperplastic bile duct cells. Whereas, in the experimental healthy groups 50,100 and 200 (Fig. H7-9) no expression of TGF- $\beta$ was observed in hepatocytes around the central vein and other hepatocytes.

The results of a-SMA expression in Nizimuddinia zanardinii hydroalchoholic extract treatment, sham and control groups are shown in Fig. I.

As indicated in Fig. I, histopathological assessment based a-SMA expression, it was observed a few expression of a-SMA in the control group (Fig. I1). On the other hand, in the BDL group (Fig. I3) significant expression of a-SMA in hepatocytes and hyperplastic bile ducts are shown. In addition, the treatment 50 group (Fig. 14) showed significant expression of a-SMA in hepatocytes and hyperplastic bile duct cells, in the treatment 100 and 200 groups (Fig. 15 \& 6) was observed mild expression of a-SMA in hepatocytes and hyperplastic bile duct cells. Also, in the experimental healthy groups (Fig. 17-9) a-SMA expression was observed only to a small extent in the central venous wall. 


\section{Discussion}

In this study, bile duct ligation was induced in rats, to evaluate the hepatoprotective and antifibrotic effect of Nizimuddinia zanardinii ethalonic extract on cholestatic liver fibrosis. As expected, BDL markedly increased the serum levels of ALT, AST, ALP, cholesterol, triglyceride, total bilirubin whereas decreased the levels of total protein and albumin in the serum and decreased the activity of CAT and SOD enzymes in the liver tissue in the cholestatic group rats. Treatment of BDL rats with Nizimuddinia zanardinii extract likely attenuated this pattern by its antioxidant effects. Bile duct ligation also induced a significant collagen deposition and proliferation of biliary epithelial cells in the liver. Some studies reported that $N$. zanardinii have the fucoxanthin and antioxidant properties and evaluated the hydroperoxy sterol cytotoxic activity extracted from this algae $[40,41]$.

The measurement of serum levels of AST, ALT and ALP uses as a mean of indirectly evaluating the liver condition. After 45 days of the experiment, the BDL groups showed enhancing in the plasma levels of ALP, AST and ALT. It is well known that hydrophobic and toxic bile acids accumulation in a cholestatic liver can lead to decreased hepatocyte membrane integrity due to oxidative stress. Therefore, ALT and AST enzymes, which are existed in liver cells with high concentrations, permeate into the bloodstream [8]. Treatment of BDL groups with Nizimuddinia zanardinii significantly decreased the levels of ALT, AST and ALP in the serum.

In the present study total bilirubin significantly increased in BDL group. The total bilirubin elevation in the serum is the major index for cholestasis. In the cholestatic liver, the conjugated bilirubin excretion decreases and as a consequence, it comes back into a serum. Although the mechanism is unclear, it is probably due to the weak connections between hepatocytes that bilirubin is released back into the serum. In addition, elevated serum bilirubin levels in the BDL group may be due to a slowing of the mating rate due to hepatocellular damage [8]. Treatment of BDL groups with Nizimuddinia zanardinii significantly decreased total bilirubin in the serum, which demonstrates the antioxidative effects of $N$. zanardinii and its protective role in the cellular membranes. On the other hand, bile acids can disrupt cell membrane function and enhance the production of reactive oxygen species (ROS), which in turn oxidatively modifies lipids, proteins, and causes hepatocyte apoptosis. All of these changes lead to impaired liver function and increased levels of ALT, AST, and low serum albumin [42]. Because, brown algae are a rich source of antioxidant compounds [43] include polyphenols, carotenoids, tocopherols, terpenes, ascorbic acid and alkaloids. These compounds react rapidly with reactive oxygen species, such as hydroxyl radicals, superoxide, and peroxide, which are themselves formed as a result of oxidative damage to human cells by endogenous and exogenous agents. This reaction delays or reduces oxidation and also prevents a wide range of human diseases [44]. In recent years due to the reduced use of synthetic antioxidants such as butyl hydroxyl toluene (BHI) and butyl hydroxy anisole (BHA), using new sources with antioxidant and antimicrobial properties, such as natural compounds found in brown algae increased. Natural plant-based antioxidants can react quickly with free radicals to suppress them [45]. In this study also albumin decreased in the BDL group compared to the sham group and Nizimuddinia zanardinii increased this index in the treatment groups. 
The experimental model of bile duct ligation has been reported to be associated with the reduce antioxidant activity of SOD and CAT in the liver [46]. In agreement with the results of other studies, in this study, cholestasis significantly reduced the SOD and CAT activities in BDL group, whiles treatment with $N$. zanardinii enhanced these enzymes activities in treatment groups. Detoxifying free radicals and preventing oxidative stress have significant roles of SOD and CAT in cholestatic liver fibrosis [8]. These observations that SOD and CAT levels were enhanced to their normal levels in the treatment of BDL rats with $N$. zanardinii, shows that the liver is reform to its normal activity through the hepatoprotective function of $N$. zanardinii.

Oxidative stress plays a key role in the development of fibrosis in the liver and other organs. Using the BDL model, the researchers showed that liver protective agents could also have antifibrotic effects. The rationale for using antioxidants is that oxidative stress is associated with increased TGF- $\beta 1$, and antioxidants interfere with the fibrogenesis process by inhibiting TGF- $\beta 1$ (Lee et al., 2007). The Nizimuddinia zanardinii possibly maintains the membrane strength of hepatocytes by regulating the redox status of cell membrane proteins and reducing the oxidation of fatty acids, and inhibits the differentiation of HSC cells into myofibroblasts [41].

In this study, in order to evaluate the antifibrotic effect of Nizimuddinia zanardinii using immunohistochemical staining, the expression of the most important fibrogenic factors including a-SMA and TGF- $\beta 1$ in liver tissue was investigated. Based on the results, the expression of a-SMA fibrogenic factor in the control and healthy experimental groups treated with different doses of Nizimuddinia zanardinii were only slightly positive in the central vein wall; while a-SMA expression in the BDL group was significantly positive in hepatocytes and hyperplastic bile ducts. In BDL groups, damaged hepatocyte cells and Kupffer cells, release several prophylactic cytokines, the most important of which is TGF- $\beta 1$ [47].

However, the liver fibrosis mechanism is not quite understood, the important role of activated hepatic stellate cells in the synthesis and deposition of connective tissue in fibrogenesis is clear.

Transdifferentiation of quiescent hepatic stellate cells may be the product of fibroblasts that express aSMA. The hepatic stellate cells activation includes increased cell proliferation, increased extracellular matrix protein synthesis, and expression of a-SMA activation marker [48]. In cholestatic liver, a-SMA is also found in myofibroblasts and fibrous areas. In agreement with the results of this study, the research of Aksua et al [48] showed that bile duct obstruction (BDL) in rats after 14 days increased the activity of liver enzymes, gamma glutamyl transferase and serum bilirubin. Also, increased expression of a-SMA was observed especially in vascular smooth muscle cells and fibrotic areas as well as around the proliferated bile duct [48]. In the present study, the expression of a-SMA in the treatment groups with Nizimuddinia zanardinii decreased in a dose-dependent manner. In the treatment BDL group with Nizimuddinia zanardinii at a dose of $200 \mathrm{mg} / \mathrm{kg}$ bw was decreased the expression of a-SMA between 3$33 \%$. In addition, cholestasis induction also increased the expression of fibrogenic factor TGF- $\beta 1$ in the BDL group. Based on our results, the expression of TGF- $\beta 1$ in the healthy experimental groups treated with Nizimuddinia zanardinii at doses of 50,100 and $200 \mathrm{mg} / \mathrm{kg}$ bw was similar to the negative control group, while the expression of TGF- $\beta 1$ in the BDL group was significantly increased around the central 
vein and bile duct cells. TGF- $\beta 1$ is one of the most important fibrogenic factors involved in HSC and is a potent mediator in extra cellular matrix (ECM) accumulation. TGF- $\beta 1$ on the one hand activates collagen production, fibronectin and proteoglycans, and on the other hand, inhibits collagen breakdown by reducing the activity of the matrix metalloproteinase and increasing the activity of metalloproteinase inhibitors. All of these actions together promote the phenomenon of fibrogenesis, and there is growing evidence that TGF- $\beta 1$ plays a key role in the formation of fibrous tissue, especially in the liver and lungs, following chronic inflammation [49].

The results of various studies showed that in animal models of bile duct obstruction, hepatic expression of TGF- $\beta 1$ mRNA increases approximately 2-4 times [49]. TGF- $\beta 1$, on the other hand, increases the synthesis of a1-type protocollagen in cultured HSC cells, resulting in the spread of liver fibrosis [50]. Increased TGF- $\beta 1$ in transgenic rats also leads to extensive hepatic fibrosis [51]. Based on the immunohistochemical results of this study, treatment of BDL rats with ethanolic extract of Nizimuddinia zanardinii at doses of 50,100 and $200 \mathrm{mg} / \mathrm{kg} \mathrm{bw}$, inhibited the expression of TGF- $\beta 1$ in a dose dependent pattern in the liver.

Based on our histopathological results, BDL significantly caused hepatic fibrosis, which determined by collagen accumulation in trichrome staining. Conversely, this effect was significantly reduced by $N$. zanardinii treatment. $N$. zanardinii also reduced the other pathologic scores of the cholestatic liver injury like necrosis infiltration of inflammatory cells and bile-duct hyperplasia.

\section{Conclusion}

The biochemical and histopathological results of this study determined the hepatoprotective and antifibrotic effects of Nizimuddinia zanardinii extract in the cholestatic liver. Based on this study, the $N$. zanardinii extract may protect the liver and have anti-fibrotic effects through its antioxidant, free radical scavenging, cell membrane protection, and inhibition of satellite cells activation and reduced expression of $\alpha-S M A$ and TGF- $\beta 1$ fibrotic factors.

\section{Declarations}

\section{Conflict of interest}

None of the authors had a conflict of interest concerning this paper.

\section{References}

1. Dyrszka, H., Salen, G., Zaki, F.G., Chen, T., Mosbach, E. Hepatic toxicity in the rhesus monkey treated with chenodeoxycholic acid for 6 months: biochemical and ultrastructural studies. Gastroenterol. 70, 93-104 (1976).

2. Greim, H., Trülzsch, D., Czygan, P., Rudick, J., Hutterer, F., Schaffner, F., et al. Mechanism of cholestasis: 6 . Bile acids in human livers with or without biliary obstruction. Gastroenterol. 63, 846- 
850 (1972).

3. Hohenester, S., Kanitz, V., Kremer, A.E., Paulusma, C.C., Wimmer, R., Kuehn, H., et al. Glycochenodeoxycholate Promotes Liver Fibrosis in Mice with Hepatocellular Cholestasis. Cells. 9, 281 (2020).

4. Chen, W.Y., Chen, C.J., Liao, J.W., Mao, F.C. Chromium attenuates hepatic damage in a rat model of chronic cholestasis. Life Sci. 84, 606-614 (2009).

5. Cruz, A., Padillo, F.J., Granados, J., Túnez, I., Muñoz, M.C., Briceño, J., et al. Effect of melatonin on cholestatic oxidative stress under constant light exposure. Cell Biochemistry and Function: Cellular biochemistry and its modulation by active agents or disease. 21, 377-380 (2003).

6. Faubion, W.A., Guicciardi, M.E., Miyoshi, H., Bronk, S.F., Roberts, P.J., Svingen, P.A., et al. Toxic bile salts induce rodent hepatocyte apoptosis via direct activation of Fas. J Clin Invest. 103, 137-145 (1999).

7. Han, J.M., Kim, H.G., Choi, M.K., Lee, J.S., Park, H.J., Wang, J.H., et al. Aqueous extract of Artemisia iwayomogi Kitamura attenuates cholestatic liver fibrosis in a rat model of bile duct ligation. Food Chem Toxicol. 50, 3505-3513 (2012).

8. Ale-Ebrahim, M., Eidi, A., Mortazavi, P., Tavangar, S.M., Tehrani, D.M. Hepatoprotective and antifibrotic effects of sodium molybdate in a rat model of bile duct ligation. J Trace Elem Med Biol. 29, 242-248 (2015).

9. Knodell, R.G., Ishak, K.G., Black, W.C., Chen, T.S., Craig, R., Kaplowitz, N., et al. Formulation and application of a numerical scoring system for assessing histological activity in asymptomatic chronic active hepatitis. Hepatology. 1, 431-435 (1981).

10. Cameron, G., Oakley, C.L. Ligation of the common bile duct. J pathol bacteriol. 35, 769-798 (1932).

11. Dong, R., Luo, Y., Zheng, S. a-SMA overexpression associated with increased liver fibrosis in infants with biliary atresia. J Pediatr Gastroenterol Nutr. 55, 653-656 (2012).

12. Huang, C.C., Chuang, J.H., Huang, L.L., Chou, M.H., Wu, C.L., Chen, C.M., et al. The human Delta-like 1 homologue is implicated in the progression of liver fibrosis in biliary atresia. J Pathol. 202, 172-179 (2004).

13. Ramm, G.A., Nair, V.G., Bridle, K.R., Shepherd, R.W., Crawford, D.H. Contribution of hepatic parenchymal and nonparenchymal cells to hepatic fibrogenesis in biliary atresia. Am J Clin Pathol. $153,527-535$ (1998).

14. Xu, F., Liu, C., Zhou, D., Zhang, L. TGF- $\beta$ /SMAD pathway and its regulation in hepatic fibrosis. J Histochem Cytochem. 64, 157-167 (2016).

15. Dillon, S., Tobias, J.D. Ondansetron to treat pruritus due to cholestatic jaundice. J Pediatr Pharmacol Ther. 18, 241-346 (2013).

16. Zandi, K., Tajbakhsh, S., Nabipour, I., Rastian, Z., Yousefi, F., Sharafian, S., et al. In vitro antitumor activity of Gracilaria corticata (a red alga) against Jurkat and molt-4 human cancer cell lines. Afr j biotechnol. 9, 6787-6790 (2010). 
17. Manilal, A., Sujith, S., Kiran, G.S., Selvin, J., Shakir, C., Gandhimathi, R., et al. Biopotentials of seaweeds collected from southwest coast of India. J Mar Sci Technol. 17, 67-73 (2009).

18. Silva, G., Pereira, R.B., Valentão, P., Andrade, P.B., Sousa, C. Distinct fatty acid profile of ten brown macroalgae. Rev Bras Farmacogn. 23, 608-613 (2013).

19. Simopoulos, A. The importance of the ratio of omega-6/omega-3 essential fatty acids. Altern Med Rev. 8, 83-84 (2003).

20. Chandini, S.K., Ganesan, P., Bhaskar, N. In vitro antioxidant activities of three selected brown seaweeds of India. Food Chem. 107, 707-713 (2008).

21. Wehr, J.D. Algae: Anatomy, Biochemistry, and Biotechnology by Barsanti, L. \& Gualtieri, P. J Phycol. 43, 412-414 (2007).

22. Dembitsky, V.M., Maoka, T. Allenic and cumulenic lipids. Progress in lipid research. 46, 328-375 (2007).

23. Nomura, M., Kamogawa, H., Susanto, E., Kawagoe, C., Yasui, H., Saga, N., et al. Seasonal variations of total lipids, fatty acid composition, and fucoxanthin contents of Sargassum horneri (Turner) and Cystoseira hakodatensis (Yendo) from the northern seashore of Japan. J. Appl. Phycol. 25, 11591169 (2013).

24. Gura, K.M., Duggan, C.P., Collier, S.B., Jennings, R.W., Folkman, J., Bistrian, B.R., et al. Reversal of parenteral nutrition-associated liver disease in two infants with short bowel syndrome using parenteral fish oil: implications for future management. Pediatrics. 118, e197-e201 (2006).

25. Antebi, H., Mansoor, O., Ferrier, C., Tetegan, M., Morvan, C., Rangaraj, J., et al. Liver function and plasma antioxidant status in intensive care unit patients requiring total parenteral nutrition: comparison of 2 fat emulsions. J Parenter Enteral Nutr. 28, 142-148 (2004).

26. Cavicchi, M., Beau, P., Crenn, P., Degott, C., Messing, B. Prevalence of liver disease and contributing factors in patients receiving home parenteral nutrition for permanent intestinal failure. Ann Intern Med. 132, 525-532 (2000).

27. Hamza, A., Hegazi, M., Youness, E., Ahmed, H. Brown Algae as A Golden Mine For Treatment of Liver Fibrosis: A Proposal Based on Experimental Animal Study. Int J Curr Pharm Rev Res. 6, 225-236 (2015).

28. Karthikeyan, R., Somasundaram, S., Manivasagam, T., Balasubramanian, T., Anantharaman, P. Hepatoprotective activity of brown alga Padina boergesenii against CCl4 induced oxidative damage in Wistar rats. Asian Pac j trop med. 3, 696-701 (2010).

29. Uchinami, H., Seki, E., Brenner, D.A., D'armiento, J. Loss of MMP 13 attenuates murine hepatic injury and fibrosis during cholestasis. Hepatology. 44, 420-429 (2006).

30. Salehi, P., Sonboli, A., Eftekhar, F., Nejad-Ebrahimi, S., Yousefzadi, M. Essential Oil Composition, Antibacterial and Antioxidant Activity of the Oil and Various Extracts of Ziziphora clinopodioides subsp. rigida (B OISS.) R ECH. f. from Iran. Biol Pharm Bull. 28, 1892-1896 (2005).

31. Lim, S., Cheung, P., Ooi, V., Ang, P. Evaluation of antioxidative activity of extracts from a brown seaweed, Sargassum siliquastrum. J Agric Food Chem. 50, 3862-3866 (2002). 
32. Moss, D.W. Clinical enzymology. Nature. 233, 505 (1971).

33. Aebi, H. Catalase in vitro. Methods in enzymology. 105: Elsevier; 1984. p. 121-6.

34. Erisgin, Z., Atasever, M., Cetinkaya, K., Dizakar, S.Ö.A., Omeroglu, S., Sahin, H. Protective effects of Nigella sativa oil against carboplatin-induced liver damage in rats. Biomed Pharmacother. 110, 742747 (2019).

35. Pan, M., Song, Y.L., Xu, J.M., Gan, H.Z. Melatonin ameliorates nonalcoholic fatty liver induced by high-fat diet in rats. J Pineal Res. 41, 79-84 (2006).

36. Sant'Anna, L.B., Cargnoni, A., Ressel, L., Vanosi, G., Parolini, O. Amniotic membrane application reduces liver fibrosis in a bile duct ligation rat model. Cell Transplant. 20, 441-453 (2011).

37. Balta, C., Herman, H., Boldura, O.M., Gasca, I., Rosu, M., Ardelean, A., et al. Chrysin attenuates liver fibrosis and hepatic stellate cell activation through TGF- $\beta /$ Smad signaling pathway. Chem Biol Interact. 240, 94-101 (2015).

38. Qun-yan, Y., Bei-li, X., Ji-yao, W., Hong-chun, L., Shun-cai, Z., Chuan-tao, T. Inhibition by curcumin of multiple sites of the transforming growth factor-beta1 signalling pathway ameliorates the progression of liver fibrosis induced by carbon tetrachloride in rats. BMC Complement Altern Med. 12, 1-11 (2012).

39. Dong, Z., Yao, D., Wang, Y., Shen, J., Zhang, C., Huang, H., et al. Abnormal expression of hepatic transforming growth factor- $\beta 1$ at the early stage of hepatocellular carcinoma formation. Mol. Cancer. 4, 91-96 (2008).

40. Fariman, G.A., Shastan, S.J., Zahedi, M.M. Seasonal variation of total lipid, fatty acids, fucoxanthin content, and antioxidant properties of two tropical brown algae (Nizamuddinia zanardinii and Cystoseira indica) from Iran. J Appl Phycol. 28, 1323-1331 (2016).

41. Moghadam, M.H., Firouzi, J., Saeidnia, S., Hajimehdipoor, H., Jamili, S., Rustaiyan, A., et al. A cytotoxic hydroperoxy sterol from the brown alga, Nizamuddinia zanardinii. DARU Journal of Pharmaceutical Sciences. 21, 24 (2013).

42. Tayyar, A.T., Kozalı, S., Yetkin Yildirim, G., Karakus, R., Yuksel, I.T., Erel, O., et al. Role of ischemiamodified albumin in the evaluation of oxidative stress in intrahepatic cholestasis of pregnancy. $J$ Matern. -Fetal Neonatal Med. 32, 3836-3840 (2019).

43. Duan, X.J., Zhang, W.W., Li, X.M., Wang, B.G. Evaluation of antioxidant property of extract and fractions obtained from a red alga, Polysiphonia urceolata. Food chem. 95, 37-43 (2006).

44. Kokilam, G., Vasuki, S., Sajitha, N. Biochemical composition, alginic acid yield and antioxidant activity of brown seaweeds from Mandapam region, Gulf of Mannar. J Appl Pharm. Sci. 3, 99-104 (2013).

45. Cox, S., Abu-Ghannam, N., Gupta, S. An assessment of the antioxidant and antimicrobial activity of six species of edible Irish seaweeds. Int Food Res J. 17, 205-220 (2010).

46. Orellana, M., Rodrigo, R., Thielemann, L., Guajardo, V. Bile duct ligation and oxidative stress in the rat: effects in liver and kidney. Comp Biochem Physiol C Pharmacol Toxicol Endocrinol. 126, 105-111 (2000). 
47. Lee, U.E., Friedman, S.L. Mechanisms of hepatic fibrogenesis. Best Pract Res Clin Gastroenterol. 25, 195-206 (2011).

48. Aksu, B., Umit, H., Kanter, M., Guzel, A., Aktas, C., Civelek, S., et al. Effects of methylene blue in reducing cholestatic oxidative stress and hepatic damage after bile-duct ligation in rats. Acta histochemica. 112, 259-269 (2010).

49. Chen, M.H., Chen, J.C., Tsai, C.C., Wang, W.C., Chang, D.C., Tu, D.G., et al. The role of TGF- $\beta 1$ and cytokines in the modulation of liver fibrosis by Sho-saiko-to in rat's bile duct ligated model. J. Ethnopharmacol. 97, 7-13 (2005).

50. Borthwick, L.A., Gardner, A., De Soyza, A., Mann, D.A., Fisher, A.J. Transforming growth factor- $\beta 1$ (TGF- $\beta 1$ ) driven epithelial to mesenchymal transition (EMT) is accentuated by tumour necrosis factor a (TNFa) via crosstalk between the SMAD and NF-KB pathways. Cancer microenvironment. 5, 45-57 (2012).

51. Sanderson, N., Factor, V., Nagy, P., Kopp, J., Kondaiah, P., Wakefield, L., et al. Hepatic expression of mature transforming growth factor beta 1 in transgenic mice results in multiple tissue lesions. Proc Natl Acad Sci. 92, 2572-2576 (1995).

\section{Table 1}

Table 1 is not available with this version.

\section{Figures}



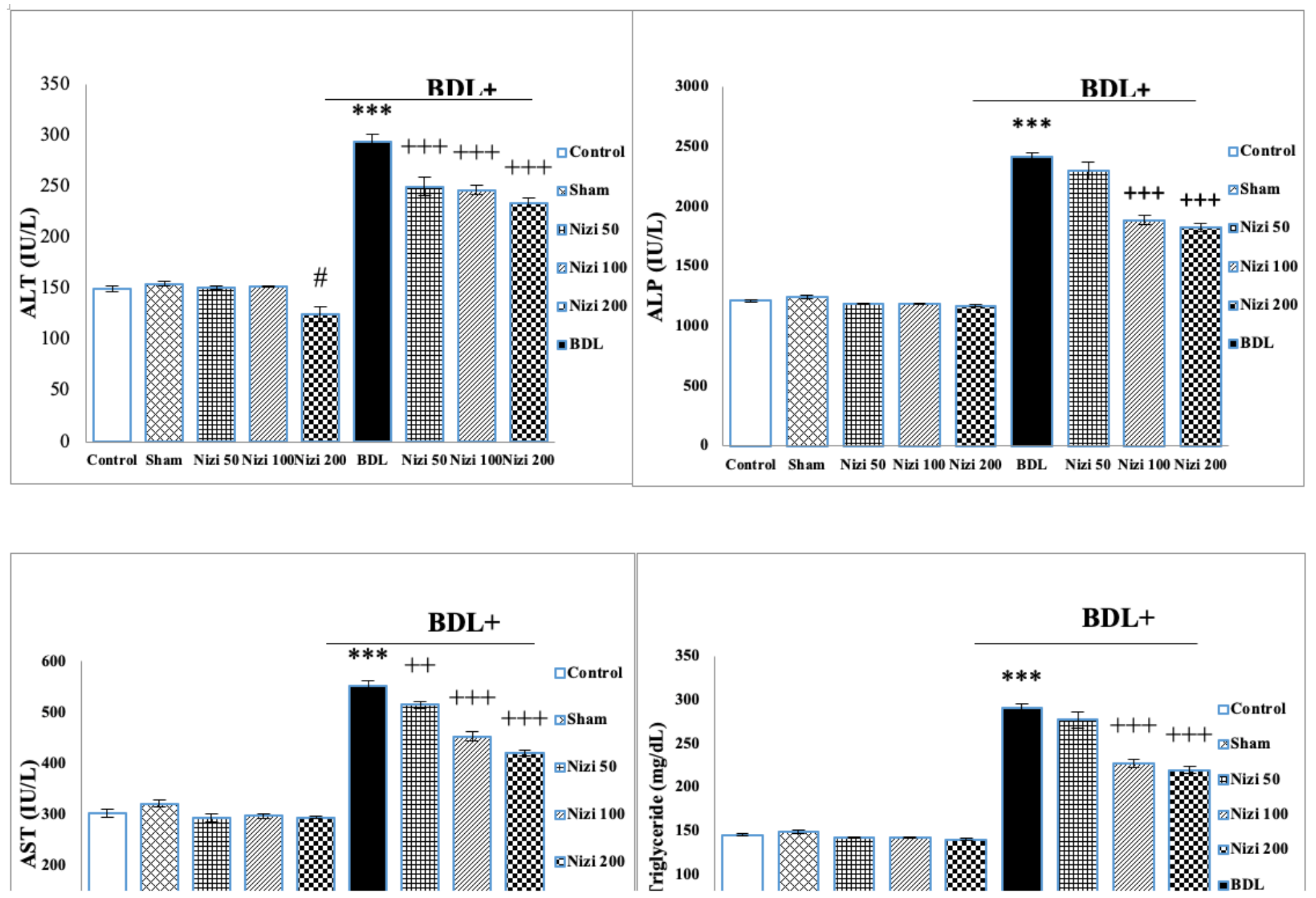

\section{Figure 1}

Figure A. Effect of Nizimuddinia zanardinii hydroalchoholic extract on ALT, AST, ALP and triglyceride indexes in BDL-induced liver fibrosis in rats. Data are expressed as mean $\pm S E M .{ }^{\#} P<0.001,{ }^{\star \star \star *} P<0.001$, ${ }^{+++} P<0.001$ and ${ }^{++} P<0.01$ compared with control, sham and BDL groups, respectively $(n=6)$.

\section{Figure 2}

Figure B. Effect of Nizimuddinia zanardinii hydroalchoholic extract on serum biochemical indexes in BDLinduced liver fibrosis in rats. Data are expressed as mean \pm SEM. ${ }^{\#} P<0.001,{ }^{\star \star *} P<0.001,{ }^{+++} P<0.001$ and ${ }^{++} \mathrm{P}<0.01$ compared with control, sham and BDL groups, respectively $(n=6)$. 

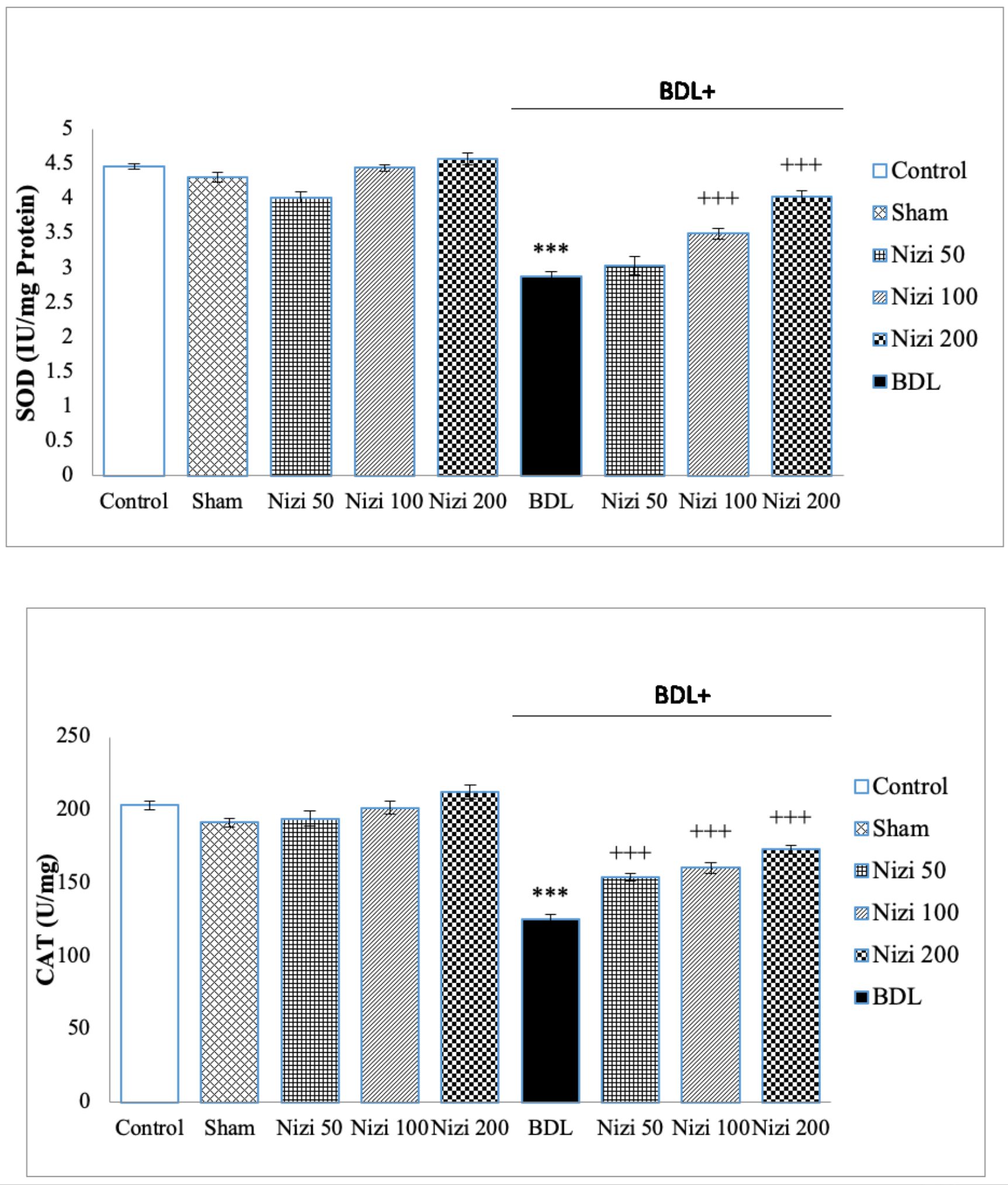

Figure 3

Figure C. Effects of Nizimuddinia zanardinii hydroalchoholic extract on antioxidant enzymes in BDLinduced liver fibrosis in rats. Data are expressed as mean \pm SEM. ${ }^{\star \star *} \mathrm{P}<0.001$ and ${ }^{+++} \mathrm{P}<0.001$ compared with sham and BDL groups, respectively $(n=6)$. 


\section{Figure 4}

Figure D: The effect of ethanolic extract of Nizimuddinia zanardinii in doses of 50, 100 and $200 \mathrm{mg} / \mathrm{kg}$ body weight on liver fibrosis due to bile duct obstruction in different groups.

\section{Figure 5}

Figure E: Histopathological findings of BDL-induced liver fibrosis in rats. 45 days after the experiment, hepatic tissue samples were evaluated Masson's trichrome staining. (1) Control, (2) Sham, (3) BDL, (4-6) BDL+ Nizimuddinia zanardinii (50, 100 and $200 \mathrm{mg} / \mathrm{kg}$ respectively), Control + Nizimuddinia zanardinii (50, 100 and $200 \mathrm{mg} / \mathrm{kg}$ respectively) (7-9). No histopathological changes were observed in liver tissues with control (1) and sham (2) the central vein (CV) and hepatocytes are all seen in a normal pattern. In the BDL group (3) infiltration of connective tissue as complete walls (arrowheads) are shown. All these lesions were markedly attenuated in Nizimuddinia zanardinii treatment (4-6) (Trichrome * 100). 
BDL+

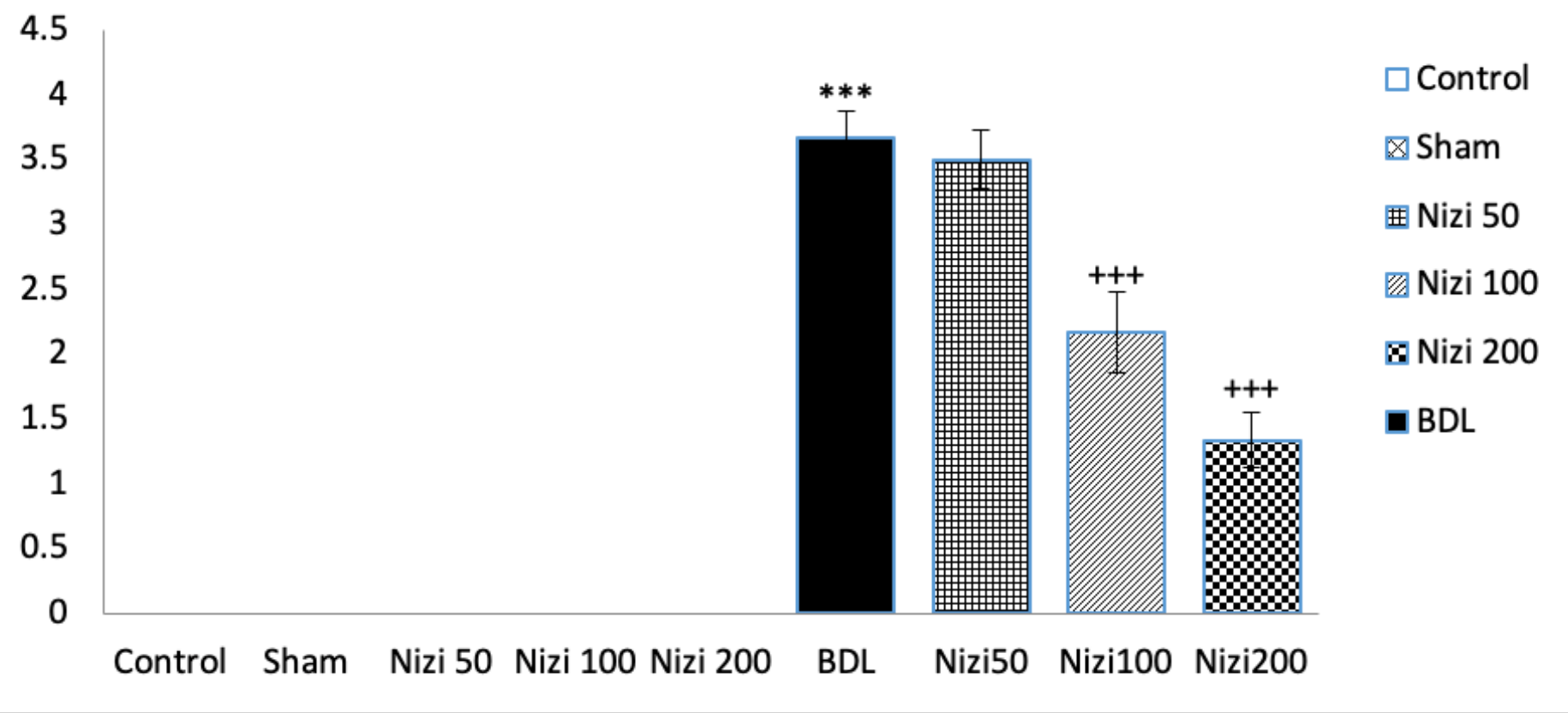

Figure 6

Figure F: Effects of Nizimuddinia zanardinii hydroalchoholic extract on TGF- $\beta 1$ expression. 


\section{BDL+}

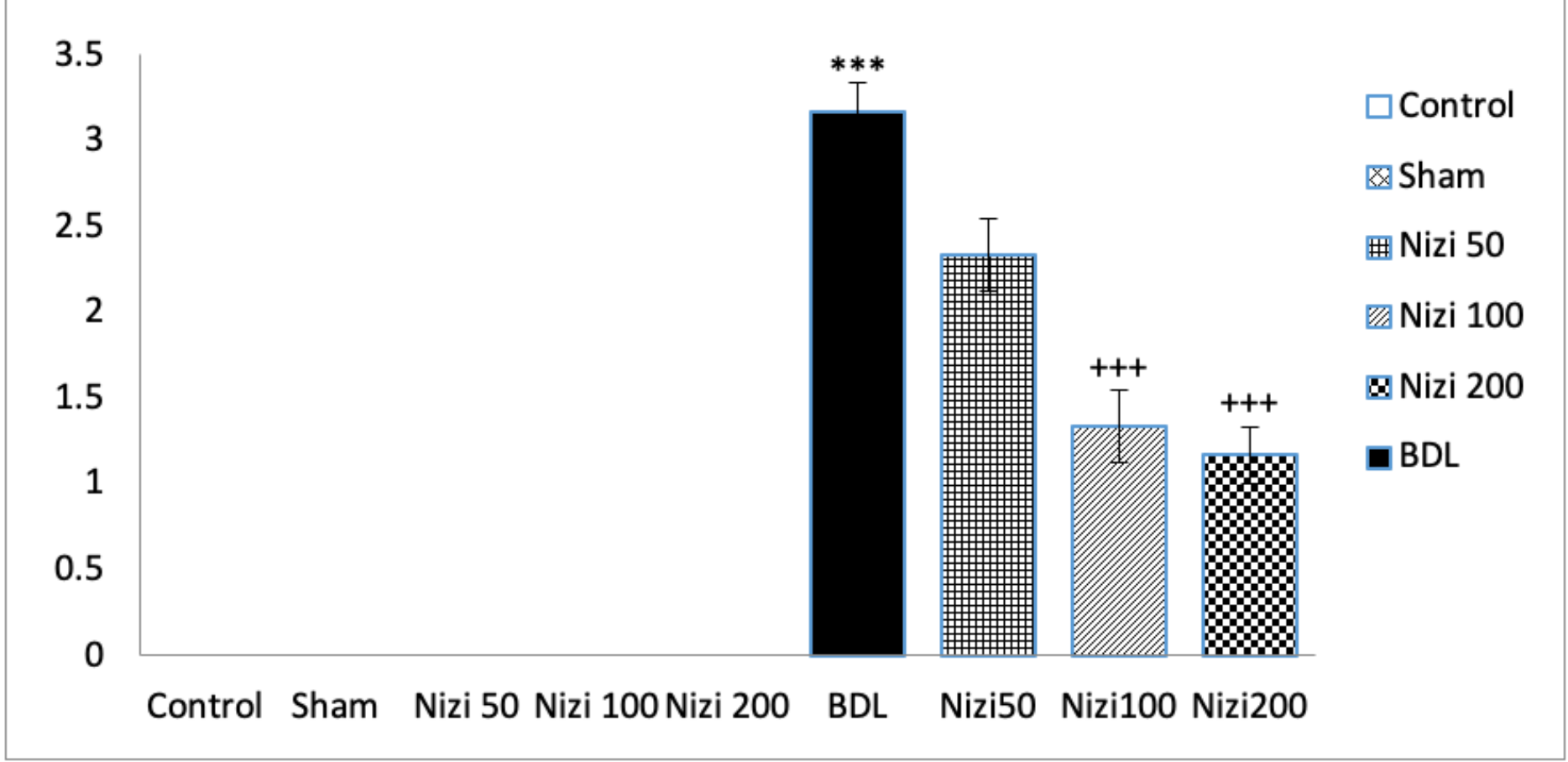

Figure 7

Figure G: Effects of Nizimuddinia zanardinii hydroalchoholic extract on a-SMA expression.

\section{Figure 8}

Figure $\mathrm{H}$. Histopathological finding with immunohistochemistry (IHC) staining based TGF- $\beta 1.45$ days after the experiment, hepatic tissue samples were evaluated by staining of IHC. (1) Control, (2) Sham, (3) BDL, (4-6) BDL+ Nizimuddinia zanardinii (50, 100 and $200 \mathrm{mg} / \mathrm{kg}$ respectively), (7-9) Control + Nizimuddinia zanardinii $(50,100$ and $200 \mathrm{mg} / \mathrm{kg}$ respectively) (IHC *400).

Figure 9 
Figure I. Histopathological finding with immunohistochemistry staining based a-SMA. 45 days after the experiment, hepatic tissue samples were evaluated by staining of IHC. (1) Control, (2) Sham, (3) BDL, (46) BDL+ Nizimuddinia zanardinii (50, 100 and $200 \mathrm{mg} / \mathrm{kg}$ respectively), (7-9) Control + Nizimuddinia zanardinii $(50,100$ and $200 \mathrm{mg} / \mathrm{kg}$ respectively). The expression of a-SMA only slightly in the central vein (CV) wall (arrow) observed in liver tissues with control (1) $(\mathrm{IHC} * 400)$. 